\title{
Research and Practical Thinking of Residential Interior Design Based on Earthquake Disaster Prevention
}

\author{
Min Zhang, Hua Huang \\ (Jingdezhen Ceramic Institute, 333001, Jingdezhen, Jiangxi, China)
}

Key words: earthquake disaster prevention; residential interior design; practical thinking

\begin{abstract}
Earthquake disaster is ruthless, in the process of defense of the earthquake disaster, in addition to the housing structure of the defense measures, the residential room should also be the corresponding design. In particular, with the rapid development of the construction industry, the continuous improvement of the level of construction technology, the increasing use of urban areas and the rapid expansion of population, high-rise buildings become the main architectural form. Therefore, residential design based on earthquake disaster prevention has important practical significance.
\end{abstract}

\section{Introduction}

China's earthquake disaster is more frequent, we also in the seismic zone, the probability of occurrence of earthquake is high. Once the earthquake disaster occurs, it may bring the huge harm , not only will cause huge losses of property, and even threaten the lives of the people's safety . Therefore, it is necessary to strengthen the earthquake disaster prevention. Especially in the current high-rise buildings to become the main form of the construction industry under the new situation, how to protect the seismic capacity of housing construction, how to enhance the housing residential seismic performance, not only in the housing construction design and other aspects of scientific optimization. It should be in the residential room for the corresponding design. The current people for the building seismic capacity awareness, but also only stay in the structure of housing construction, residential design optimization is not on the agenda. This paper will focus on the analysis of residential and interior design based on earthquake disaster prevention .

\section{Foothold of Residential Interior Design Based on Earthquake Disaster Prevention}

Residential interior design optimization, in order to be able to enhance its seismic performance, reduce the threat of earthquake disasters,it is the current new proposition. In the building construction of the earthquake disaster prevention, people pay more attention to the housing structure of the building optimization and housing construction process of many norms, but the residential interior design concern is still relatively low. Based on this, in the process of residential interior design, we need to scientifically grasp its foothold, in order to better enhance the scientific design of residential interior, and effectively avoid the hazards of earthquake disasters.

\subsection{From the Point of View of How to Protect People's Security}

The basic foothold in residential interior design, is concerned about people's safety, which is the construction industry, " people-oriented " concept is deepening. People are emotional and rational co-dominant high-level animals, when the earthquake occurred, people will be under the guidance of self-consciousness, choose the way they think the most secure . But it is only 12 seconds to feel the time of the earthquake from the earthquake to the destroying of the building in earthquake, and it seems unrealistic to escape from a short period of time, especially for high-rise buildings . Therefore, how to choose a strong triangle area, how to avoid the risk of falling objects, how to quickly and accurately find a safe location, which requires the design of the residential room , based on the earthquake disaster prevention considerations, planning of various functional areas scientifically . At the same time, in the residential interior design process, need to reduce the threat of earthquake disaster, but also need to do a good job of furniture and interior structure of the 
scientific design, especially furniture materials . [Tuo Binbin, Wang Yinzhen, Zengchun , Research on Earthquake Disaster Prevention in Urban Residential Area Planning [J] , Architectural Design Management, 201301 . ] . A sturdy furniture can effectively form a safe area . Once the building is earthquake damage, to avoid falling objects and the emergence of the injured, smashed, provide a reasonable shelter for people to wait for the rescue .

\subsection{From the Perspective of Reducing Secondary Disasters}

Based on the purpose of earthquake disaster prevention, in the process of residential interior design, the design of the foothold also includes the purpose of reducing the secondary disaster for the effective design of the residential room. When people are indoors, in the event of an earthquake, people can not flee to the outdoors in time, in order to reduce the earthquake damage to people, but also to avoid people in the escape, asylum and other minor injuries in the process, which requires the residential room reasonable allocation of functions, from the non-structural parts, partitions, materials and other aspects to optimize the design, to give people a clear psychological hint, to avoid unnecessary escape and trampling and other bad incidents . Practice has proved that scientific residential interior design can effectively reduce the threat to secondary disasters to people, but also to give people full confidence, so that they can remain calm and restraint, choose a safe refuge area, waiting for the arrival of rescue workers .

\section{Practice of Residential Interior Design Based on Earthquake Disaster Prevention}

Enhance the seismic capacity of housing construction, reduce the threat to earthquakes to people , in addition to the design and optimization of the foothold on the structure of housing construction, but also should pay more attention to the residential interior of the scientific design . Practice from the residential interior functional division, the design of indoor furniture and furnishings, the choice of interior design materials .

\subsection{Reasonable Division of Different Functional Areas in Residential}

In order to meet people's living needs and other needs of life, residential interior design process , often divide a certain functional area, in order to meet people's diverse needs, such as wet and dry areas, recreation areas and rest areas . Based on the purpose of earthquake disaster prevention, in the residential interior functional area division, we should proceed with the following aspects . First, the design of the channel. In the design of the indoor functional area, you should change the traditional design concept of space utilization, but should reserve a certain channel, the concept of multiple entrance to the main living space layout. Secondly, in order to prevent the indoor components in the strong shaking of the earthquake collapsed other secondary disasters, giving a certain threat, so the design for the partition, should reduce the use of brick structure . Partition can exist, can also be directly removed. If the partition must exist, then the partition or furniture should be used to carry out artificial freedom of the partition, as far as possible no longer use the mandatory structure of the brick wall partition. Thirdly, in the division of the indoor functional area, the area of the triangular support structure is relatively safe .Therefore, these areas can be fully utilized to design them into areas where people often gather, such as rest areas. So that in the event of an earthquake disaster, people can quickly access to these areas, to set aside a safe space for themselves. Fourth, in the design of the indoor structure, we should learn from the ancient aspect of the length and width ratio of scientific design, the proportion is generally $2: 1$, In the current structure of the layout and design, the general performance of the middle area for the largest and most spacious, both sides in turn reduced. So that in the event of an earthquake, what can reduce the earthquake in the shock, the building's jitter, effectively protects the safety of housing construction, but also can avoid the collapse of indoor buildings. Fifth, in the design of the indoor electrical switch, you should choose the area where people often stay, and set it in the more obvious and easy to reach the area, where should not was designed too high or too low . 


\subsection{Scientific Design of Indoor Furniture and Orderly Layout}

Based on the purpose of earthquake disaster prevention, in the process of residential interior design, furniture should also be scientific design and reasonable layout, to avoid the violent shaking, to decrease the secondary disasters for the indoor people. On the one hand, in the interior furniture design process, it should be based on the stability of furniture and stability to carry out scientific design. The current type of furniture design diversification, although beautiful, but the stability of the furniture is very low, many designers need to enhance the design efficiency, often directly using rivets fixed way, in the event of an earthquake, this structure of the furniture is prone to tear, Broken rivets on the human body damage which is relatively large . Based on this, in the design of indoor furniture, it should be " back to nature ", and it is used in the design of interior furnishings . [Lu Guangpu, the design of interior furnishings based on earthquake prevention and disaster prevention [J] , science and education , 2011 (19) : 103-104 . ] . The ancient tenon structure, the use of bump design principles to reduce the dependence on rivets, while the design also has a certain degree of flexibility, it can reduce the shape of the stress changes. On the other hand, in the layout of the furniture, based on the purpose of earthquake disaster prevention, we should avoid the furniture in a relatively sharp or sharp corner, and should protect the furniture fixed . Especially for some of the need to hang the furniture, in addition to the furniture itself, the fixed element, but also should be used for double wire fixed .

\subsection{Scientific Choice of Interior Design Materials and Use}

Based on the purpose of earthquake disaster prevention, in the process of interior design, we should also choose to design materials, enhance the stability of the indoor structure and the overall strength, reduce the threat to / from earthquake disasters . On the one hand, for the design of indoor partitions, steel structures can be used to enhance its stability and reduce the use of brick walls. At the same time it can also be used to laminate rubber material flexible structure, or to achieve the effective combination of the two, in order to comprehensively enhance the overall strength of residential non-structural components. On the other hand, in the main material of the main bearing wall selection, we should choose to use excellent performance, stable and reliable materials, so as a whole to enhance the overall performance of the indoor load-bearing walls . In addition, the choice of interior design materials, but also should try to choose some good fire resistance materials, heat resistance of the relatively good materials to avoid the emergence of indoor fire, giving serious secondary disasters .

\section{Conclusion}

Earthquake disaster is more frequent, the current people in the design of earthquake disaster prevention, mainly focus on the structural design of housing and related mandatory norms . But the scientific residential interior design itself can reduce the degree of harm to the earthquake disaster, so as to effectively protect the people's lives and property safety .

\section{References:}

[1] Tuo Binbin, Wang Yinzhen, Zengchun, urban residential area planning in the earthquake disaster prevention [J], Architectural Design Management, 201301 period.

[2] Lu Guangpu, Mao Qihong, based on earthquake disaster prevention of residential interior design research [J], science and education, 2011 (19): 103-104. 